\title{
Pensar las Humanidades en la Universidad: perspectivas a contraluz
}

Juan Sebastián Ballén Rodríguez ${ }^{1}$

\begin{abstract}
Resumen
La intención de esta investigación es la de mostrar que las relaciones entre las humanidades, la universidad y la educación se producen a través de las conexiones con el arte, el símbolo, la metáfora y la virtualidad, escenarios discursivos y técnicos a través de los cuales se han formulado una serie de proyectos de humanización, visibles en las propuestas filosóficas de Werner Jaeger, Enríque Rodo, Edwar Said, Jacques Derrida y Lluís Duch. La pluralidad de estas apuestas teóricas pondrán de presente un efecto de perspectiva a contraluz, que interpretará las relaciones entre las humanidades y la universidad, en el devenir histórico del capitalismo.
\end{abstract}

Palabras clave: humanismo, educación, universidad, capitalismo, paideia, América Latina, colonialidad, Oriente, Europa, deconstrucción. 


\title{
Current challenges to education in times of uncertainty.
}

\begin{abstract}
This essay aims to show that the relationships between the humanities, the university and education are produced through connections with art, the symbol, the metaphor and the virtual as scenarios of discourse and technique. A series of projects for humanization have been formulated through them, as can be seen in the philosophical proposals of Werner Jaeger, Enríque Rodo, Edward Said, Jacques Derrida and Lluis Duch. The plurality of these theoretical proposals will show up the effects of a perspective seen against the light which will interpret the relationships between the humanities and the university in the historical development of capitalism.
\end{abstract}

Keywords: humanism, education, university, capitalism, Paideia, Latin America, colonial ethos, East, Europe, deconstruction.

Recibido: 10-02-2014

Aceptado: 02-04-2014

En una Universidad en la que las decisiones sobre la investigación y la docencia son anónimas -o aparentemente anónimas- $\mathrm{y}$ en la que las opiniones científicas, los puntos de vista, las prioridades, ya no se imponen por su fuerza de convicción sino por medios administrativos -la decisión del «grupo»- ya no tienen sentido el ethos personal universitario y científico, pues lo relevante es la decisión del «grupo», que es anfibio, esto es, jerárquico y anónimo.

Rafael Gutiérrez Girardot (1986:64)

\section{Problemática}

Martha Nussbaum en su libro Sin fines de lucro. Por qué la democracia necesita de las humanidades (2010), diagnostica que la crisis que ha movido las bases de las sociedades altamente industrializadas, no se encuentra en las sucesivas crisis económicas originadas a partir del 2008; en su lugar, plantea que la profundidad de la crisis tiene su origen en el modelo de educación que se le imparten a las nuevas generaciones, las cuales, están siendo orientadas hacia un tipo de formación altamente instrumental, donde se troquela el carácter de individuos 
diestros técnicamente, careciendo del conocimiento de las humanidades, parte fundamental del pilar que sostendría una sociedad democrática, habitada por ciudadanos que piensan por sí mismos y poseen las capacidades suficientes para deliberar.

Para Nussbaum las preferencias materiales que se imponen cada vez más en las universidades norteamericanas ${ }^{2}$, son una prueba de la dificultad de acceder a un tipo de formación que privilegie otro tipo de saberes, como es el caso del acceso al conocimiento del alma del otro. Siguiendo los planteamientos de Tagore, Nussbaum considera que la categoría de alma no hace referencia a algún tipo de cualidad divina privilegiada, sino que alude al despliegue de las facultades de la imaginación y del pensamiento, actividades que se encuentran al servicio de la sociabilidad y la cultura. La imaginación y el pensamiento son las exclusivas humanas necesarias en la construcción de una auténtica noción de democracia. Estas mismas facultades se desarrollarían ampliamente en la enseñanza de las artes y las humanidades, de ahí que su existencia en los planes curriculares de las universidades tenga como propósito la potenciación del pensamiento crítico, además del conocimiento del otro y de las problemáticas que se desprenden del cosmopolitismo y el derecho internacional.

A juicio de la filósofa, en la actualidad resulta necesario aplicar la distinción entre una educación para la «obtención de renta» y otra para la «ciudadanía integradora». Esta diferencia le permitirá a la sociedad valorar el papel de las artes y las humanidades como saberes fundamentales en la construcción de la ciudadanía. La razón de ser de las humanidades en la universidad es la de fomentar la actitud crítica o el «estado de alerta». A través de los conocimientos humanísticos es posible el acceso al mundo del otro en sus especificidades culturales, situando la reflexión desde el complejo escenario donde se consolidan las relaciones de interdependencia económica. Para Nussbaum estas disciplinas no se marginan de las exigencias económicas que alimentan la estabilidad de las democracias, ya que proveen de la imaginación y la creatividad, habilidades necesarias para las futuras generaciones de trabajadores, a quienes se les ha interiorizado la idea de la prosperidad económica.

En el siguiente análisis se propondrá la tesis de que las humanidades son pliegues a contraluz del conocimiento, que versan fundamentalmente sobre la «[...] ‘decisiva' pregunta socrática de cómo queremos vivir» (Walzer \& Seel, 2007: 14). Son un conjunto diverso de saberes que potenciarían el modo simbólico de pensar, porque recurren a la metáfora, el arte y el símbolo como principales recursos técnicos para la significación humana de la realidad. Un pensar que se caracterizaría por dos elementos que actúan mutuamente: la reflexividad,

2. Nussbaum se refiere a los informes realizados en los Estados Unidos entre el 2007 y 2008 , y en los que se hacen balances y diagnósticos de la educación superior. Los resultados confirman la paulatina desaparición de las humanidades y la consolidación de una forma estandarizada de conocimiento, que si bien es discutida por los profesores en diversos centros de enseñanza en la secundaria de este país, sin embargo, es apoyada por los padres de familia, las grandes compañías y por los mismos estudiantes, a quienes se les ha inculcado la idea de que el reconocimiento social pasa necesariamente por la prosperidad económica. 
volcada hacia la comprensión de lo humano, bajo la égida de las artes y las letras, y el sentimiento de humanización o empatía, experiencia humana atada a la capacidad comunicativa, esto es, al uso del lenguaje con miras a la consolidación de un proceso de interacción con otras formas de representación simbólica y donde tienen lugar la sociabilidad y la cultura.

Tanto la reflexividad como la empatía configuran la mirada a contraluz $z^{3}$ que proyectarían las humanidades hacia la realidad. Una mirada que en lugar de reflejar lo que acontece, lo que hace es crear el efecto de la luz contraria, distorsionando la significación «literal» o la imposición del «hecho», para pasar al plano de la simbolicidad y la metáfora.

En este trabajo se describirán cinco posibles proyectos de humanidad, que a través de sus lógicas particulares ven en el arte, la metáfora y el símbolo, recursos técnicos para una visión a contraluz. El efecto a contraluz se interpreta como las posibilidades que se abren para las humanidades de profesar otros lenguajes en la universidad, alternos, no solo al proceso de la tecnificación que atraviesan las sociedades en su obligada participación en las dinámicas del mercado global, sino también al proceso de la «democratización» vivida al interior de la universidad, y que ha sido, a juicio del filósofo colombiano Rafael Gutiérrez Girardot, un proceso alterno de «burocratización», en el que se sustituyen el ethos de las personalidades científicas, las cuales animarían la confrontación de las escuelas del pensamiento, por la organización de los «grupos», masa multiforme de profesionales que se encuentran para formar «redes de conocimiento», por lo general entes abstractos, excesivamente burocratizados dados los protocolos de control que establecen los «centros de investigación», órganos estatales creados para la observación y la vigilancia.

Las humanidades a contraluz escaparían de la democratización de las prácticas burocráticas en las que vive atrapada la universidad de hoy, al tiempo que reconocerían el talante teórico de las personalidades científicas que, a lo largo de la historia del pensamiento, han leído las mutaciones del sistema económico capitalista. No pueden ser, como considera Nussbaum, ámbitos del saber necesarios para perfeccionar la capacitación técnica de los futuros trabajadores en materia de imaginación y creatividad.

Desde la perspectiva de Werner Jaeger se retoma el concepto de paideia griega, modelo educativo que reivindica el ideal de la cultura helénica volcada hacia el cultivo de las letras antiguas (el griego y el latín), la filosofía y la plasticidad del cuerpo. En esta tradición las humanidades y la filología clásica van de la mano, de tal suerte que las principales tesis del filósofo helenista están ambientadas por un aire historicista y academicista, en la que el humanista deviene en una especie 
de investigador de las primeras fuentes (paleografía y archivística), y cuya tarea será la de cotejar las obras egregias de la antigüedad griega, para luego significarlas en el presente. Esta visión eurocéntrica asume que los antecedentes culturales de la vieja Europa tienen en la Grecia antigua un modelo educativo de obligada consulta para las jóvenes generaciones.

En un segundo momento, se hace alusión a la obra de Enrique Rodó Ariel, que a comienzos del siglo XIX, se convierte en el texto fundacional para una entusiasta «ola» de pensadores latinoamericanistas que proclaman por un modelo cultural alimentado de la diversidad simbólica que ha constituido la mezcla de las razas (mestizaje), en respuesta a la problemática epocal acerca de la identidad del hombre latinoamericano, confrontada con la idiosincrasia pragmática y utilitaria de la estirpe norteamericana.

Luego se problematizará el concepto de las humanidades en la tradición de los estudios culturales, prestando atención a los trabajos adelantados por el pensador palestino Edward Said, quien para mediados de los años 80 y bajo el influjo metodológico de Michel Foucault, propone una lectura crítica del discurso humanista de Occidente, el cual desde el siglo XVIII ha creado una seudorepresentación del otro oriental. El origen y el rendimiento de la discusión planteada por Said, tiene en la universidad el principal eco de resonancia, pues es el espacio académico el que pondrá de presente que la relación entre la modernidad y la colonialidad, el imperio y la cultura, es una lógica civilizatoria que niega el valor epistémico y axiológico de categorías caras al pensador palestino como lo son las de pluralidad, diversidad, cotidianidad, historia y periferia.

En un cuarto análisis se describe la noción de las nuevas humanidades, desarrollada por el filósofo francés Jacques Derrida, y que cobra especial relevancia en la discusión librada en la universidad actual sobre la vigencia de las ciencias humanas y de su talante performativo, frente al predominio de las ciencias exactas y de los saberes instrumentales, cuya pretensión epistémica busca la constatación y la objetividad.

Finalmente se explora la dimensión salvífica y religiosa de una noción de humanidades que fincada en la antropología educativa, propende por una resemantización de las gramáticas del futuro (las nuevas tecnologías), a través de una hermenéutica del fenómeno religioso que presta atención a la redención y la esperanza que se desprende del lenguaje simbólico.

En las conclusiones se hará una propuesta tentativa del que hacer de las humanidades en la universidad, retomando los aportes examinados por las propuestas filosóficas esbozadas. 


\section{La humanidad posible en la «invención cultural griega»: el helenismo de Werner Jaeger}

Dentro del movimiento helenista de la primera mitad del siglo XX se destacan las investigaciones de Werner Jaeger (1888-1961) y Ulrich von WilamowitzMoellendorff (1848-1931), notables representantes de la escuela filológica alemana. El primero de ellos, reconocido por su monumental Paideia. La formación del hombre griego, llevará a cabo una recuperación del concepto de educación entre los griegos, para significarlo como un proceso proteico de civilización, inspirado en las potencias de la filosofía, la biología, la medicina, la gimnasia, la música, la escultura, la poesía, la épica, la tragedia y la geometría. El cultivo de las disciplinas liberales y mecánicas entre los griegos, definirán el saber cultural en occidente. La Grecia antigua se convierte en un modelo cultural, porque su historia es el relato de un ideal de humanidad que rebasa la barbarie, gracias a que la humanización es definida como un acto educativo en el que el hombre tiene la posibilidad de inventar técnicamente (artísticamente) su $v i^{4}{ }^{4}$. La educación es el instrumento a través del cual el hombre, como paciente y agente del acto formativo, hace parte de un proceso cultural de transformación espiritual y corporal:

Todo pueblo que alcanza un cierto grado de desarrollo se halla naturalmente inclinado a practicar la educación. La educación es el principio mediante el cual la comunidad humana conserva transmite su peculiaridad física y espiritual. Con el cambio de las cosas cambian los individuos. El tipo permanece idéntico. Animales y hombres, en su calidad de criaturas físicas, afirman su especie mediante la procreación cultural. El hombre sólo puede propagar y conservar su forma de existencia social y espiritual mediante las fuerzas por las cuales las ha creado, es decir, mediante la voluntad consciente y la razón [...] Incluso la naturaleza corporal del hombre y sus cualidades puede cambiar mediante una educación consciente y elevar sus capacidades a un rango superior. Pero el espíritu humano lleva progresivamente al descubrimiento de sí mismo, crea, mediante el conocimiento del mundo exterior e interior, formas mejores de la existencia humana (Jaeger, 1997: 3).

En el modelo de la paideia griega, la educación se propuso en principio la transformación corporal y espiritual de los hombres. En otras palabras la

4. A juicio de Olaf Gigon, el gran descubrimiento filológico de Jaeger en la Paideia consistió en mostrar que uno de los cometidos culturales de los griegos fue el de la «formación de un hombre perfecto y verdadero» (Gigon, 1965: 631) entendiendo con ello que la existencia del hombre cobraba sentido en la medida en que respondía a una tarea de embellecimiento artesanal: en otras palabras, devenir hombre entre los griegos es igual a hacer de la vida humana una auténtica obra de arte. Esta idea antropogenética se ubica más allá de las constelaciones culturales creadas en otros lugares del orbe: «Más allá del persa, del griego y del romano, más allá del general, del médico y del arquitecto, estaba el hombre perfecto sin más, cuyo ideal había que realizar. Nosotros agregamos que esta educación para lograr el hombre perfecto, al menos a partir de la filosofía ática, se entiende como un arte en sentido riguroso. La vida del hombre se concibe como obra de arte que hay que crear. Esto está implícito en la pregunta de Aristóteles, muy simple pero en modo alguno comprensible de suyo, de si existe una tarea o labor específica del hombre, así como la hay del carpintero o zapatero. También está esto implícito en la muy citada formación estoica, según la cual la filosofía moral sería el arte (técnica) de la plasmación de la vida» (Gigon, 1965: 644). 
educación es entendida como una actividad integradora de las facultades humanas. Esta concepción parte del presupuesto de que la educación es un proceso de transformación que va más allá del proceso de hominización; es en la humanización donde el hombre podrá elevar a un rango superior sus capacidades; mientras que en la hominización los cambios están sujetos a la evolución, proceso en el que los seres vivos luchan por la supervivencia, la humanización está orientada a los cambios en los modos de existencia que libra el hombre con su entorno y consigo mismo: el ser social y el cultivo de sí mismo serán dos factores determinantes en la diferencia que separa al hombre del animal: «La naturaleza del hombre, en su doble estructura corporal y espiritual, crea condiciones especiales para el mantenimiento y la trasmisión de su forma peculiar y exige organizaciones físicas y espirituales cuyo conjunto denominamos educación» (Jaeger, 1997: 3).

En la concepción antropocentrista de la educación que se respira en la paideia griega, son denominadores comunes a su forma espiritual la creatividad y la plasticidad, elementos que conjuntamente consolidan un proceso de vivificación que identifica las peculiaridades culturales de una comunidad. La plasticidad del mundo griego alude a la capacidad que tiene el ser humano para materializar sus facultades intelectuales. Este proceso se identifica en las obras de los clásicos de la antigüedad, como La Iliada y La Odisea de Homero, La teogonía y los Trabajos y los días de Hesiodo, la lírica de Safo, Los Diálogos de Platón, La Metafísica de Aristóteles, La Orestiada de Esquilo, El Edipo Rey de Sófocles, etc.

Estas obras son referentes de las hazañas, los dramas, las tragedias y el pensamiento sobre el cual, querámoslo o no, se ha cimentado las bases culturales y lingüísticas de Occidente. Esta objetivación espiritual llevada a cabo en la tradición de la antigua Grecia no renuncia en el esfuerzo de poner el conocimiento y la voluntad, en dirección a la realización de la totalidad de las potencias espirituales y corporales, que vistas en conjunto reconstruyen la visión sustancial del hombre desde la idea de humanidad, que marcará la historia de Occidente hasta la modernidad:

En la educación, tal como la practica el hombre, actúa la misma fuerza vital, creadora y plástica, que impulsa espontáneamente a toda especie viva al mantenimiento y propagación de su tipo. Pero adquiere en ella el más alto grado de su intensidad, mediante el esfuerzo consciente del conocimiento y de la voluntad dirigida a la consecución de un fin (Jaeger, 1997: 3).

En la paideia griega Jaeger encuentra un pretexto para afirmar que los matices antropológicos de los diferentes pueblos no pueden renunciar a un ideal de formación, donde la armonización del cuerpo y el alma se convierten en la teleología educativa por excelencia. En este sentido la transformación física y 
mental, no está sujeta a una raza destinada a realizar la idea de la humanidad, como se llegó a pensar durante el siglo XIX bajo el concepto de la «invención griega», sino más bien a la praxis histórica que realiza vitalmente un pueblo. Esta praxis pone en juego las ideas y los valores en una actividad educativa que los griegos concibieron bajo el concepto de paideia:

Historia significa, por ejemplo, la exploración de mundos extraños, singulares y misteriosos. Así la concibe Heródoto. [...] Pero es preciso distinguir la historia en este sentido casi antropológico, de la historia que se funda en una unión espiritual viva y activa y en la comunidad de un destino, ya la del propio pueblo o la de un grupo de pueblos estrechamente unidos. Sólo en ésta clase de historia se da una íntima inteligencia y un contacto creador entre unos y otros. Sólo en ella existe una comunidad de ideales y formas sociales y espirituales que se desarrollan y crecen independientemente de las múltiples interrupciones y variaciones a través de las cuales una familia de pueblos de distintas razas y estirpes varía, se entrecruza, choca, desaparece y se renueva (Jaeger, 1997: 5).

La historia abandona el papel de maestra de los relatos de los pueblos y de sus especificidades culturales, para ser definida como una ciencia humana que da cuenta de la idea general de la humanidad. El humanismo se plantea como un telar de inteligibilidad con miras a la inserción del otro bajo el modelo de la racionalidad dialógica. La fascinación que produce la hondura y riqueza espiritual del pueblo griego en la antigüedad consistió en su capacidad para recrear los grandes problemas del ser humano, como lo fueron el significado del pensamiento ideal frente a la creencia y la opinión desde los diálogos de Platón, la problematización metafísica del ser como idea o cambio en la perspectiva de los naturalistas Parménides y Heráclito, la ceguera moral y el destino en las tragedias de Esquilo y Sófocles, hasta la conflictiva relación que testimonian los grandes poemas Homéricos entre los dioses y los hombres; en la filosofía, la literatura y la ciencia además de afirmarse la idiosincrasia de un pueblo, se construye la idea universal de humanidad.

Una de las críticas que se le plantea a la teoría historicista de la paideia griega, consiste en su marcado eurocentrismo, pues en el reconocimiento de las bondades culturales de un pueblo, se propone paralelamente una teleología educativa para la cual toda acción racional está orientada a la transformación del animal homínido en ser humano: dicho de otro modo, el humanismo clásico que se desprende del culto al mundo griego apunta a una concepción universalista y panhelenista de la cultura en Occidente.

Los helenistas saldrán al paso de las críticas culturalistas, al plantear que el cultivo de las ciencias en la antigua Grecia es un modelo ideal de formación, porque en ella se entendió la educación como una praxis histórica de transformación, en la que el hombre lograba superar la determinación biológica 
dominada por la «animalidad individualizada», para ser definida como una persona que universaliza un pensamiento, una acción moral ejemplar o una técnica, y mediante la cual puede ser reconocida como una «totalidad absoluta».

El humanismo helenista en la perspectiva de Jaeger entiende que el hombre es un animal simbólico que despliega sus potencias en el arte, la técnica, la poesía, la filosofía, la política, la economía, etc. El ser genérico, es la categoría que explica la potenciación de la diversidad de las facultades humanas (pensar, sentir y actuar), perfeccionadas a través de la praxis educativa, la cual no está anclada al idealismo de la «objetivación espiritual», sino al humanismo, doctrina que se remonta desde la tradición latina a Varrón y Cicerón, y mucho antes a las enseñanzas de los maestros y filósofos griegos (Homero, Sócrates y Platón), coincidiendo ambas aristas culturales en el predicamento de que el hombre no es un individuo particular sino un ideal universal de perfección (ser genérico):

(...) Su descubrimiento del hombre no es el descubrimiento del yo objetivo, sino la conciencia paulatina de las leyes generales que determinan la esencia humana. El principio espiritual de los griegos no es el individualismo, sino el «humanismo», para usar la palabra en un sentido clásico y originario, Humanismo viene de humanitas. Esta palabra tuvo, por lo menos desde el tiempo de Varrón y de Ciceron, al lado de acepción vulgar y primitiva de lo humanitario, que no nos afecta aquí, un segundo sentido más noble y riguroso. Significó la educación del hombre de acuerdo con la verdadera forma humana, con su auténtico ser. [...]. No surge de lo individual, sino de la idea. Sobre el hombre como ser gregario o como supuesto yo autónomo, se levanta el hombre como idea. A ella aspiraron los educadores griegos, así como los poetas, artistas y filósofos. Pero el hombre, considerado en su idea, significa la imagen del hombre genérico en su validez universal y normativa (Jaeger, 1997: 12).

Tanto Jaeger como Wilamowitz defenderán una concepción de las humanidades en estrecha relación con el método historicista de la filología clásica alemana. Para Gigon (1965), es un método exegético dirigido principalmente a desentrañar el sentido histórico de los textos, entendido como un esfuerzo por saber varias cosas: primero, cómo se ha originado una época histórica en el documento antiguo; segundo, cual ha sido la «intencionalidad» del autor del texto al escribirlo; tercero, de qué formas ha influido la «obra» en los contemporáneos y las siguientes generaciones; y cuarto, relacionar cómo las huellas del presente son los rastros marcados por el pasado (cf. Gigon. 1965: 632-633).

Detrás del historicismo humanista que se respira en la paideia griega, se identifica una suerte de «culturología clásica», que se esmera en relacionar las realizaciones griegas con el devenir histórico y cultural de Europa (cf. Gigon, 1965: 632-633). 


\section{Arielismo: la mirada rodoniana de las humanidades en América Latina}

El Ariel (1900) del uruguayo José Enrique Rodo (1871-1917), es una obra de finales del siglo XIX, de gran resonancia en la juventud latinoamericana de la época. Bajo un estilo que combina la reflexión filosófica con el recurso literario, es un libro inspirado tanto en los ideales de una generación de entusiastas por desentrañar las raíces culturales de los pueblos suramericanos, como también un manifiesto que se levanta contra las contradicciones sociales latentes en las realidades políticas de los países latinoamericanos. Responde, efectivamente, a los vientos de cambio defendidos por una legión de latinoamericanistas, quienes pensaron los asuntos de la identidad cultural, la relación entre la civilización y barbarie, el imperialismo del coloso del norte y la emergencia de los ideales revolucionarios de liberación. Entre los hechos sociales que acompañaron estas preocupaciones filosóficas, se destacan los acontecimientos desencadenados en Cuba con el movimiento independentista que lideró José Martí, y que reverterían posteriormente la situación de «dominación imperial» vivida en la isla, al ser a finales del siglo XIX, la última colonia de ultramar atada a los rezagos del antiguo régimen español.

Así mismo, este ensayo es una respuesta desde el sur de Latinoamérica a las crecientes pretensiones expansionistas de los Estados Unidos, que para la época y hasta la fecha, ha proyectado para América Latina una serie de políticas policivas encaminadas al control de los gobernantes y de sus poblaciones: $E l$ Ariel será una respuesta que reacciona críticamente ante el ímpetu de dominación del país del norte, que como se suele decir, ha hecho de los países del Caribe y de todo el sur del continente su patio trasero.

La referencia a la obra de William Shakespeare es una constante en el libro de Rodó. Desde el título mismo, la figura es tomada de la obra dramática La tempestad, y donde el escritor uruguayo identifica a tres personajes que escenificarían tres modelos de cultura: Próspero, Ariel y Calibán. El primero es el maestro sabio, representante de la sabiduría greco-latina y cristiana y cuya tarea es la de orientar e instruir al joven Ariel, quien vendría a encarnar el espíritu de la belleza, la ingenuidad y las posibilidades del futuro; y Calibán, su contradictor, imagen de la fealdad moral y sobre todo de la condena del hombre a ser un esclavo de los intereses de la vida material.

La lucha entre Ariel y Calibán reproduce la lucha entre la civilización y la barbarie: una idea de civilización que para Rodo nutriría a Latinoamérica desde lo más granado de la tradición griega y latina, el Siglo de Oro español y en general la cultura hispánica en su aspecto literario y católico, con la nobleza y la fortaleza de los primeros pobladores de las tierras americanas. De otra parte, la barbarie estaría dada por la cultura de la industrialización, la ciencia y la técnica, instrumentos idóneos para la transformación del homo ocioso al 
homo faber: modelo de humanidad caracterizado por la pobreza espiritual, bajo la promesa utilitaria de garantizar la felicidad social a través de la cultura del trabajo, principal fuente de la prosperidad material. Calibán es un interlocutor de las filosofías anglosajonas y norteamericanas: del empirismo y el utilitarismo en su versión inglesa, combinado con el pragmatismo y el liberalismo de cuño norteamericano.

La lucha entre Ariel y Calibán es entonces la lucha entre un modelo de cultura $\mathrm{y}$ de vida que privilegia la belleza, las artes y las letras en general, con otro que se impone desde los países del norte, y que implementaría el espíritu de la industriosidad, a través del fomento de los saberes técnicos y del cultivo de la ciencia. La confrontación entre estos personajes es también la dramatización del proyecto de modernización de los países latinoamericanos, arrasando con la cultura letrada (el cuidado de la lengua) y las fuentes católicas de la tradición hispánica (la moral del honor y la hidalguía).

En esta medida la figura del Ariel, es un símbolo que hace referencia a la cultura como un saber valioso por su tradición, donde la juventud latinoamericana encontrará los sentidos definitorios para un modo de ser bello y armónico, enriquecido por los ideales filosóficos y literarios de Grecia y Roma, y provisto de los valores morales de la hidalguía cristiana representada por el héroe literario del siglo de oro español: Don Quijote de la Mancha.

Así las cosas, pensar las humanidades en clave rodoniana, implicaría reconocer dos elementos:

a) El símbolo y la metáfora identificarían la forma excelsa de pensar, sentir y hablar sobre lo latinoamericano. No es entonces el lenguaje referencial y técnico el que describiría los deseos y las contradicciones que habitan al interior de las juventudes latinoamericanas, sino más bien la forma vedada e insinuante de los símbolos y las metáforas. Estos símbolos anclarían el modo de ser latinoamericano con una historia o tradición que rescata la relación entre la verdad, la belleza y la bondad moral.

b) Es en el espíritu joven donde conviven y se armonizan los ideales de verdad, belleza y bondad moral. Pensar, sentir y hablar de lo latinoamericano cobra vida y sentido en la medida en que las nuevas generaciones se apropian del saber tradicional y proyectan cambios y transformaciones que modificarán las circunstancias de analfabetismo, dominación y explotación que han caracterizado históricamente la imposición de las estructuras de dominación imperial en su doble aspecto moderno-colonial. 


\section{Las humanidades y la colonialidad del poder}

Orientalismo (1978), del filósofo palestino Edward Said (1935-2003), es una obra donde se propone la tesis de que Occidente se ha creado no solamente a partir de una perspectiva material de dominación sobre las colonias de ultramar y las civilizaciones orientales, sino que se ha visto a sí misma a contraluz de Oriente, creando con ello una seudo-imágen de la orientalidad. Esto quiere decir que Occidente es un contenido representacional que funciona de manera inversa a Oriente: Oriente es la imagen invertida de Occidente, en donde el primero es el antecedente originario, su génesis e infancia, y el segundo es su continuación más refinada, madura y moderna.

La imagen que se proyecta de revés tiene como propósito la construcción de un ámbito de dominación donde el «otro» es el espejo de un «sí mismo», en el que se replican las formas de pensar, de educar, de producir riqueza y en general de hacer sociedad según el modelo cultural de Occidente. Este fenómeno ha sido descrito a través de la categoría de la «colonialidad del poder».

Ahora bien, esta construcción del «otro oriental»', hace parte de la pretensión de dominación de Occidente, y que Said denomina bajo la categoría de «colonialidad». Castro-Gómez enfatiza en la lectura que hace Said sobre la estrategia de dominación que llevó a cabo Occidente en el siglo XIX, y que consistió en la creación de cátedras de estudios en «civilizaciones antiguas». Es en esta misma época donde la filología se convierte en la disciplina humanística por excelencia, además del surgimiento de otras ciencias subalternas como la antropología, la paleontología, la etnología, la geografía y la historia.

El estudio de las lenguas antiguas, es, a juicio de uno de los pioneros del orientalismo académico, William Jones (1746-1794), un trabajo arqueológico donde se pone de presente que las lenguas latinas y la griega provienen de un mismo tronco lingüístico: el sanscrito. Este gesto académico puso de presente que el antecedente cultural de Europa se encontraba en oriente. Sin embargo, como ya lo hubiese reconocido Hegel en sus Lecciones de historia universal, si Oriente es la infancia de la humanidad, esto es, su principio cultural, Occidente, sería su continuación y telos: si la aurora de los tiempos iluminó a Oriente, es en el ocaso donde la plena realización de un origen primitivo se proyectará sobre una luz madura que ha iluminado sobre Occidente.

De este modo la perspectiva sobre Oriente se enmarcó en la linealidad histórica de Occidente, que se manifiesta en la racionalidad científico-técnica de la modernidad (cf. Castro-Gómez, 2010: 45). El retorno a las civilizaciones antiguas no fue otra cosa que la actualización de un presente desconocido para Occidente, y el cual, «preparó» el terreno para consolidar un proyecto de humanización, que incluye el estudio de las tradiciones «primitivas», su exotismo, su magia y misterio, para luego devenir en una historia cuya meta de racionalización será 
la liberación de lo «originario», proceso de maduración, que hará participar a Oriente del proceso de modernización diseñado en Europa y los países del norte, inspirado básicamente en el conocimiento científico técnico.

Las ciencias humanas del siglo XIX nacen en el marco epistémico y geopolítico de la dominación colonial. Las ciencias humanas ponen de manifiesto la relación entre saber y poder, y esta es la nota característica de la modernidad. CastroGómez resalta que en Said se identifica la grilla entre la modernidad y la colonialidad, pues el pensador palestino plantea que el proceso de modernización ha ido acompañado por una forma de representar el mundo a la medida de los atributos de la racionalidad, la frialdad, la técnica, la cuantificación, la moral del trabajo, etc. Estos atributos se convierten en prácticas de dominación colonial, que han deslindado al otro hasta convertirlo en una "diferencia lejana», al ser nombrado bajo los calificativos de lo «exótico», lo «telúrico», el «realismo mágico», el «color del trópico», el «saber ancestral», etc.

La dominación geopolítica que ha caracterizado la territorialización de Occidente sobre Oriente, se consolida con la hegemonía económica y epistémica. Los espacios periféricos quedan relegados, y sirven como centros de abastecimiento para la recolección de materias primas al servicio de los grandes centros de producción industrial. Pero las relaciones asimétricas entre los espacios periféricos y centrales, no distan de las que se establecen entre el poder y la producción del saber científico-técnico, en contubernio con el modelo de desarrollo capitalista. Los vínculos entre el conocimiento y el poder se localizan en las grandes metrópolis, relegando a un segundo plano otros espacios donde se cocinan formas distintas de hacer ciencia y de producir materialmente la vida.

De otra parte, la dialéctica ínsita en la tesis modernidad/colonialidad, plantea que la expropiación territorial de las culturas y de las lenguas de Oriente, se lleva a cabo por cuenta de una falsa representación que crea Occidente bajo el nombre de «orientalismo», categoría empleada para ampliar el currículo de las «ciencias humanas» en el siglo XIX. Esta misma dialéctica es asumida por los estudios latinoamericanos a través de la teoría de la colonialidad (cf. CastroGómez, 2010: 47).

Cinco años después de la publicación de Orientalismo, Edward Said motivado por las conexiones explícitas en esta investigación entre los conceptos de imperio y cultura, y producto de una serie de conferencias impartidas entre 1985 y 1986 en universidades norteamericanas, canadienses e inglesas, reúne una serie de estudios con la publicación de Cultura e Imperialismo.

En esta obra se plantea la crítica a los modos de representación que han marcado a Occidente; modos que a juicio de Said se expresan de diversas formas: a través de una retórica soterrada en expresiones como «el este misterioso», la «mente africana» o el «tropicalismo latinoamericano»; en los discursos filosóficos y 
antropológicos que proponen un único modelo de civilización, relatos que traerán beneficios materiales y un refinamiento cultural, necesario para que los hombres primitivos dominados anteriormente por el estado premoderno de la barbarie, alcancen la «mayoría de edad»; a las políticas de seguridad, estructuradas en un sistema de control social basado en el castigo, que llamaría al orden cada vez que «ellos» se comporten de manera inadecuada, o no, bajo los patrones que han moldeado la conducta de «nosotros». Son materia de interés para el análisis cultural planteado por Said las construcciones discursivas y culturales que han caracterizado a los procesos de colonización en los territorios periféricos como lo son India, partes del Lejano Oriente, África, Australia y el Caribe.

Del mismo modo, hace parte del análisis el estudio de las formas de resistencia, que se manifestaron unas veces como núcleos reducidos y clandestinos, en otras como movimientos de masas con un alto sentido nacionalista, los cuales revertirán la situación de dominación. A partir de la hipótesis de que el imperialismo ha sido un proyecto político y económico que busca el dominio de las culturas por medio de un único modelo de civilización, Said propone una serie de precisiones sobre el uso que hará del concepto de cultura: básicamente la cultura son todas aquellas prácticas de descripción, comunicación y representación, que alejándose de los ámbitos sociales de la determinación económica y política, producen placer, porque contienen valores y pensamientos tanto del saber popular como del especializado:

En primer lugar, se refiere a todas aquellas prácticas como las artes de la descripción, la comunicación y la representación, que poseen relativa autonomía dentro de las esferas de lo económico, lo social y lo político, que muchas veces existen en forma estética, y cuyo principal objetivo es el placer. Incluyo en ella, desde luego, tanto la carga de saber popular acerca de las lejanas partes del mundo, como el saber especializado del que disponemos en disciplinas tan eruditas como la etnografia, la historiografía, la filología, la sociología y la historia literaria (Said, 2006: 12).

Según esta definición, los relatos (novelas) se convierten en los principales dispositivos en donde se dramatiza el proceso de planificación de una cultura a partir de un modelo civilizatorio: modelo imperialista que proyecta la administración de la tierra y el gobierno de las poblaciones. La novela se convierte en el escenario cultural a partir del cual se toman las decisiones políticas y se libran las discusiones sobre los intereses de los colonos para alcanzar sus objetivos de dominación:

[...] mi idea principal es que los relatos se encuentran en el centro mismo de aquello que los exploradores y los novelistas afirman acerca de las regiones extrañas del mundo y también que se convierten en el método que los colonizados utilizan para afirmar su propia identidad y la existencia 
de su propia historia. En el imperialismo, la batalla principal se libra, desde luego, por la tierra. Pero cuando toca preguntarse por quien la poseía antes, quien posee el derecho de ocuparla y trabajarla, quien la mantiene, quien la recuperó y quien ahora planifica su futuro, resulta que todos esos asuntos habían sido reflejados, discutidos y a veces, por algún tiempo decididos, en los relatos (Said, 2006: 13).

Sin embargo, este concepto de cultura pone de presente que las obras de arte están al servicio de un modelo político y cultural imperante, denominado por Said como Imperialismo. La conexión entre cultura e imperio consiste en la exteriorización de un contenido ideológico y moral, descrito y defendido por las elites letradas en los países colonizadores:

En segundo lugar, la cultura es, casi imperceptiblemente, un concepto que incluye un elemento de refinada elevación, consistente en el archivo de lo mejor que cada sociedad ha conocido y pensado, según lo formulara Matthew Arnold alrededor de 1860. Arnold creía que si no neutraliza, al menos la cultura amortigua los estragos de nuestra moderna existencia urbana, agresiva, mercantil y brutalizadora. Leemos a Dante o a Shakespeare para poder seguir en contacto con lo mejor que se ha conocido y pensado, y también, para vernos, a nosotros mismos, a nuestro pueblo, a nuestra tradición, bajo las mejores luces. Con el tiempo, la cultura llega a asociarse, a veces de manera agresiva, con la nación o el estado; esto es lo que «nos» hace diferentes a «ellos», casi siempre con algún grado de xenofobia. En este sentido la cultura es una fuente de identidad; una fuente bien beligerante, como vemos en recientes retornos a tal cultura o a tal tradición. Acompaña a estos «retornos» códigos rigurosos de conducta intelectual y moral, opuestos a la permisividad asociada con filosofías relativamente liberales como el multiculturalismo y la hibridación. En el antiguo mundo "colonizado», tales «retornos» han producidos variedades de fundamentalismo religioso y nacionalista (Said, 2006: 14).

La cultura occidental puede ser caracterizada de la siguiente manera: a) refinada, en la medida que hace mención de unas obras egregias y catalogadas como clásicas, b) catártica, en tanto que ofrece mundos posibles y diferentes a la brutalidad de la realidad mercantil y urbanizada, c) autoreferente, si se considera que la lectura de Cervantes o de Dante ofrece modelos de humanización superior, donde se espera que el lector se conozca mejor a sí mismo y al mundo que le rodea, d) identitaria, en la medida que los autores clásicos harán mención de un pueblo, de unos valores y unas costumbres, en fin de un conjunto de actitudes de vida que identifican a una nación o a un Estado, y finalmente, e) fundamentalista, pues el retorno a los valores y los modos de vida tradicionales, produce códigos de conducta intelectual y moral, que se reflejarán en los movimientos ultra religiosos y pronacionalistas. 
Tal definición de cultura convierte lo propio como lo «culturalmente nuestro», es decir, asocia la identidad con el folklore nacional, hasta venerarlo como objeto de culto (autóctonismo, eurocentrismo, regionalismo, etc.). Los modelos culturales son significados como las síntesis donde se resumen los fines morales, políticos y estéticos, dignos de ser seguidos por una raza. Las humanidades son preciadas por ser el conjunto de conocimientos históricos, que actualizarán a las nuevas generaciones en la apropiación de las virtudes culturales que reposan en los grandes relatos de un pasado glorioso, sobrevalorando las producciones poéticas y filosóficas foráneas o extranjeras, hasta perder de vista que la realidad en la cual se ha erigido una sociedad está historiada a través del comercio de esclavos, la explotación y la compra de mano de obra barata, la conquista de tierras y la opresión «colonialista», etc. Las humanidades asumidas como el conjunto de conocimientos que representan la idiosincrasia de una clase, grupo o raza social, desvincula la cultura de la cotidianidad:

El problema de esta idea de cultura es que supone no sólo la veneración de lo propio sino también que eso propio se vea, en su cualidad trascendente, como separado de lo cotidiano. Así, muchos humanistas profesionales se ven incapaces de establecer conexiones entre la crueldad prologada y sórdida de prácticas como la esclavitud, o la opresión racial y colonialista, o la ejecución imperial en el seno de una sociedad, por un lado, y, por otro, la poesía, la ficción y la filosofía de esa misma sociedad. Una difícil verdad que descubri al trabajar este libro es cuán pocos de los artistas ingleses o franceses que admiro analizaban la noción de «sujeto» o de raza «inferior» dominante entre los funcionarios que practicaban esas ideas como algo asumido al gobernar Argelia o en India (Said, 2006: 14).

Mientras que los profesionales en humanidades pierden de vista las dinámicas históricas en las que el imperialismo ha producido las migraciones de poblaciones, la xenofobia, el apartheid, etc., otros relatos se están emitiendo desde las periferias excluidas y las poblaciones no reconocidas. En otras palabras, el humanista tendría que poner sus ojos en la «[...] experiencia cruzada de orientales y occidentales»:

Desde la época de Conrad a Dickens el mundo se ha transformado de maneras que muchas veces han sorprendido y alarmado a los europeos y a los norteamericanos metropolitanos; que ahora se enfrentan con vastas poblaciones no europeas que en su propio medio y con impresionante desfile de nuevas y potentes voces, que exigen que sus relatos sean escuchados. La tesis de mi libro es que esas poblaciones y esas voces hace tiempo que están allí, gracias al proceso globalizador puesto en movimiento por el imperialismo moderno. Perderemos de vista lo esencial acerca del mundo en la última centuria, si desdeñamos o no tomamos en cuenta la experiencia cruzada de orientales y occidentales, y la interpretación de los 
terrenos culturales en los cuales el colonizador y el colonizado coexisten y luchan unos con otros a través de sus proyecciones, sus geografías rivales, sus relatos y sus historias (Said, 2006: 24).

En Cultura e Imperialismo Said sostiene por tesis que la coexistencia entre los relatos de las sociedades oprimidas, con los proyectos colonialistas que hacen carrera en el «proceso globalizador» o «imperialismo moderno», trae como consecuencia el surgimiento de una cultura híbrida que, combinando la exuberancia de la naturaleza, la idiosincrasia y los deseos de cambio de las poblaciones en los espacios geográficos colonizados, se vincula con los grandes proyectos económico-políticos de dominación, prefijados por las potencias coloniales de turno. El cruce de esta hibridación cultural es susceptible de ser analizada a partir de las producciones literarias (novelas). El espacio de tiempo trazado en este estudio comprende desde los acontecimientos ocurridos en Occidente, al finalizar el proceso histórico de la guerra fría, hasta el surgimiento de los Estados Unidos como última superpotencia:

Más profundamente, este es un libro acerca del pasado y del presente, acerca de «nosotros» y de «ellos», según como los vean las partes implicadas, que son varias y habitualmente están separadas. Su momento histórico, para decirlo de algún modo, es el del periodo posterior al fin de la guerra fría, cuando Estados Unidos emerge como la última superpotencia (Said, 2006: 27).

A juicio de Said, una de las constantes de todo proceso colonizador de un imperio, es la negación sistemática de la idea pluralista de las culturas, entendidas como formas de vida ontológicamente diferenciadas y heterogéneas en su devenir histórico, en cual narra las especificidades de un modo de vida determinado por una idiosincrasia local. El imperativo político de la cosmovisión imperial consiste en la construcción imaginaria de un otro sometido al poder colonial homogeneizador. Las amenazas del antiamericanismo latente en el mundo árabe moderno responden sintomáticamente a la pretensión imperialista unidimensional de las nuevas élites coloniales.

El nacionalismo sembrado a ambos lados del océano, son el caldo de cultivo que alimenta los odios y las xenofobias culturales. Para Said, los espacios utópicos y reflexivos que propician las universidades, permitirán reflejar los problemas vitales que experimentan las comunidades segregadas. Es tarea de la universidad humanista superar los vicios académicos, los cuales se han caracterizado en Occidente por sobrevalorar los saberes y las lenguas eurocéntricas y angloparlantes, a menosprecio de los saberes ancestrales y de las prácticas religiosas locales:

En parte a causa de la existencia de los imperios, todas las culturas están en relación unas con otras, ninguna es única y pura, todas son hibridas, 
heterogéneas, extraordinariamente diferenciadas y no monolíticas. Lo cual, según creo, es verdad, tanto en los Estados Unidos de hoy como en el mundo árabe moderno; en ambas sociedades, se han temido igualmente los peligros del «antiamericanismo»y las amenazas con el «arabismo». [...] Lamentablemente, este nacionalismo defensivo, reactivo y hasta paranoide se encuentra entretejido muchas veces con la esencia misma de la educación, en la que se instruye tanto a los niños como a los estudiantes mayores en la veneración y celebración de sus tradiciones (habitualmente con la envidia y a expensas de otros). Apunto precisamente a esas formas de educación y pensamiento acríticas e irreflexivas como una alternativa paciente y modificadora, como una posibilidad francamente exploratoria. Durante el curso de escritura del libro me beneficie del espacio utópico todavía hoy accesible de la universidad, que creo que debe seguir siendo el sitio donde se investiguen, discutan y reflejen esos problemas vitales. Porque si la universidad se convierte en un lugar donde las cuestiones políticas y sociales realmente se impulsaran o se resolvieran, esto supondría liquidar su función y convertirla en algo subordinado a cualquier partido político en el poder (Said, 2006: 36).

\section{Un nuevo humanismo para la universidad sin condición}

La propuesta de un nuevo humanismo para la universidad sin condición, es la tesis defendida por Jacques Derrida (1930-2004) en la conferencia impartida en el mes de abril de 1998, en la Universidad de Stanford (California). En aquella oportunidad el filósofo francés fue invitado para ofrecer una charla sobre la relación entre las artes y las humanidades de cara a la situación que se prevé para la universidad del mañana. El título que le diera a esta conversación hace parte del ensayo que publicado posteriormente llevaría por título «La universidad sin condición» (2002).

Para el pensador francés abordar las nuevas humanidades, en el contexto de la globalización de los mercados es un acto de fe. Y es así porque discurrir sobre este tópico en el escenario de unas universidades que paulatinamente viven atadas a las condiciones impuestas por la sociedad de mercado, implica al mismo tiempo hacer las veces del ejercicio confesional («compromiso declarativo» afirma el filósofo). Ejercicio que se caracterizaría por testimoniar la vigencia de las humanidades como un acto de fe, esto es, «como si» no estuviera atada a ciertas restricciones ajenas a su propia tarea de esclarecer la verdad sobre las cuestiones del hombre.

Así las cosas, las humanidades establecerían una relación epistémica con la verdad del hombre (antropología). Una verdad que adquiere un matiz jurídico, primero en el siglo de las luces a través de la declaración de los derechos del hombre y del ciudadano, y después, en el escenario de las guerras que se librarían durante 
la primera mitad del siglo XX, conflictos históricos que darán cuenta, muy posteriormente, de una declaración universal de los derechos humanos. A partir de los derechos del hombre, las humanidades tendrían relación con el proceso histórico de la mundialización, toda vez que consideramos que la apelación a la generalidad de los hombres, es el a priori histórico que se transparenta en la declaración de los derechos del hombre y el ciudadano ${ }^{5}$.

La propuesta de las nuevas humanidades gravitaría alrededor de los asuntos del hombre. Enlazándolo con el tema jurídico que se plantearía entre las humanidades y los derechos del hombre, este saber mostraría la historia de los crímenes contra la humanidad. Las humanidades visualizarían esta historia de la atrocidad y la barbarie, no encerrándose en sí misma, sino abriéndose hacia los nuevos lenguajes tecnológicos de la comunicación. Las humanidades como productoras de los saberes archivísticos de información y de las técnicas de la comunicación, asumen el filtro y la decantación.

Las humanidades son un saber crítico o de deconstrucción. Esto quiere decir que pensarían a la universidad sin condiciones. La crítica actuaría como un derecho a deconstruir de un modo afirmativo y performativo; esto quiere decir que sus enunciados al tiempo que plasmarían un tipo de escritura particular de una tradición, crearían un acontecimiento, en otras palabras, las humanidades harían algo mientras despliegan su discurrir. Reflejar, inventar y plantear son las acciones encarnadas por la teleología educativa de una universidad llamada a pensar de modo un modo incondicional los asuntos humanos.

Entre las tareas que le corresponden a las humanidades al asumir metodológicamente la práctica de la deconstrucción, se sugiere las siguientes:

[...] al ser incondicional, semejante resistencia podría oponer la universidad a un gran número de poderes: a los poderes estatales (y, por consiguiente, a los poderes políticos del Estado-nación así como a su fantasma de soberanía indivisible: por lo que la universidad sería de antemano no solo cosmopolita, sino universal, extendiéndose de esa forma más allá de la ciudadanía mundial y del Estado-nación en general), a los poderes económicos (a las concentraciones de capitales nacionales e internacionales), a los poderes mediáticos, ideológicos, religiosos y culturales, etc., en suma, a todos los poderes que limitan la democracia por venir. La universidad debería, por lo tanto, ser también el lugar en el que nada está a resguardo de ser cuestionado, ni siquiera la figura actual y determinada de la democracia; ni siquiera tampoco la idea tradicional de crítica, como crítica teórica, ni siquiera la autoridad de la forma «cuestión», del pensamiento como «cuestionamiento» (Derrida, 2002: 14).

5. Otros antecedentes históricos explicarían la emergencia de la humanidades en el escenario de las batallas jurídicas que libraría Occidente contra otros pueblos y culturas, por ejemplo, el derecho de gentes que en los siglos XV y XVI darían cuenta de dos escenarios: la discusión sobre el derecho a la dominación de los pueblos indígenas por Bartolomé de las Casas y Juan Ginés de Sepúlveda; segundo, la interpretación del derecho a la guerra que declararía la empresa conquistadora, frente al derecho de los pueblos o «ius gentium», planteamiento jurídico sistematizado por Francisco de Vitoria, y que fue una preocupación permanente en la escuela de la tomística salmantina entre los siglos XVI y XVII. 
Las universidades sin condiciones son aquellos lugares donde nada permanece sin estar sometido a la libre indagación («pueden decirlo todo»). Derrida propone leer el ejercicio crítico de la deconstrucción como una apuesta metodológica que orientaría a las nuevas humanidades, más allá de una concepción puramente clásica del conocimiento humanístico. Una concepción clásica enfatizaría que las humanidades son un conjunto de saberes que permiten hacer ejercicios de traducción e interpretación. En su versión tradicional, las humanidades fueron concebidas como un conjunto de saberes exclusivos (latín y griego), a través de las cuales se entrenaba a un lector en los ejercicios de traducción de las obras clásicas de la tradición greco-romana; los conocimientos en gramática y retórica estaban encaminados al refinamiento en el dominio de la palabra y el gusto por lo buena conversación. La recuperación de las tradiciones y los saberes antiguos es una impronta imborrable en la formación clásica en humanidades.

Ahora bien, las humanidades asumirían la tarea de fomentar las «prácticas deconstructivas» (Derrida, 2002: 20), es decir, todas aquellas acciones concretas de aprendizaje, que cuestionarían tanto la forma tradicional en la cual se ha enseñado a clasificar y a ordenar el conocimiento (v.g. el árbol de Porfirio), como también a la forma habitual de comunicarlo (v.g. la escritura). Partiendo del hecho de que las humanidades se refieren a los asuntos del hombre desde los lenguajes de la metaforicidad y la analogicidad, las prácticas deconstructivas son vecinas a las formas de expresar y comunicar un pensamiento reflexivo ${ }^{6}$. Con la expresión «como sí», Derrida se refiere a que las humanidades harían uso verosímil de la cópula del verso ser o estar, pues en sus predicamentos es frecuente el recurso a la metaforicidad y la analogicidad. La virtualidad es otra realidad del conocimiento humano donde la información viaja a través de la metáfora y la analogía. Como lo señala el francés «La virtualidad es el nuevo abc de la deconstrucción», porque deslocaliza los discursos, las conversaciones y las discusiones.

Varias cuestiones se desprenden de este planteamiento, por ejemplo: ¿Podrían las prácticas deconstructivas negar sistemáticamente el «compromiso declarativo» que caracteriza el discurrir en las humanidades?, ¿Cuál es el horizonte pedagógico de la virtualidad en el contexto de la mercantilización de los conocimientos y de los servicios educativos, proyectos liderados por la universidad del siglo XXI?, ¿Cómo podrían las humanidades asumir el «compromiso declarativo» a través de los lenguajes multimediales?

A juicio del francés el carácter performativo de las humanidades, permitirá pasar de la «constatación de los hechos» al «compromiso declarativo»; dicho de otro

6. Uno de los antecedentes filosóficos de la estructura lingüística del «como sí», es identificado por Derrida en el juicio reflexionante y en general en la teoría del juicio de gusto estérico propuesta por Kant en la Crítica del Juicio. Para el francés el "como sí» actuaría como lo hace el juicio reflexionante, porque esta forma de proceder en el discurrir de la razón según la teoría kantiana no estaría determinada por la experiencia directa que produciría la impresión sensible del objeto, sino que, más bien, se desplegaría libremente, permitiendo a los hombres alcanzar el conocimiento de las ideas regulativas, a saber, las ideas de Dios, del mundo y del alma. Pero también señala que en esta tradición estética, las humanidades se convierten en un conocimiento histórico de refinamiento y veneración, pues su conocimiento no iría más allá de los ritos de culto y admiración producidos por la experiencia estética de la comunicabilidad de la obra de arte. 
modo, la pretensión deconstructiva es también un compromiso ético. Este que hacer ético de las humanidades se concibe en cuatro niveles: A. Las humanidades y la «práctica confesional», B. Las humanidades y la universidad soberana, C. Las humanidades, la literatura y el testimonio, y D. Las humanidades y la performatividad.

a. Las humanidades y la práctica confesional: en primer lugar, las humanidades, al ser asumidas como un acto de fe, se convierten en el confesionario de los males que han mancillado la idea de humanidad. En otras palabras, las humanidades actuarían como la «conciencia moral» que expiaría las culpas de los crímenes históricos de la esclavitud, la inquisición, los genocidios, la colonización, el apartheid, las masacres, los secuestros, las torturas, etc. Y esta práctica confesional radicalizaría la incondicionalidad de las universidades, dicho de otro modo, su «fuerza invencible» estaría justamente en no declinar ante la atracción que producen los beneficios materiales de los poderosos, quienes, al fin de cuentas, son los más interesados a que no salga a la luz la verdad sobre las maquinaciones que rodearon a los crímenes y a sus culpables.

b. Las humanidades y la universidad soberana: en segundo lugar, de la mano de la profesión de fe que hace el profesor de humanidades, se da el hecho histórico de que las universidades han sido y son espacios de soberanía, esto es, lugares donde el pensamiento goza de la absoluta independencia frente a los poderes externos que intentan acallarla o en su defecto comprarla. En este sentido a las universidades las constituye un principio de resistencia que es al mismo tiempo un principio de disidencia. Estos dos elementos harían parte de la «desobediencia civil», entendiendo con ello que las universidades sin condiciones actuarían «por mora una ley, un pensamiento y una justicia superior».

c. Las humanidades, la literatura y el testimonio: y en tercer lugar, a pesar de que goza de un cierto reconocimiento la idea de que las humanidades agruparían una serie de saberes tradicionales, las nuevas humanidades tendrían que incluir, lo que se ha dado a llamar en la tradición universitaria anglosajona como las «teorías de la traducción» (la articulación de la teoría literaria, la filosofía, la antropología, el psicoanálisis, la lingüística, etc.). La literatura y en general la teoría literaria se acomodaría al «como sí», lugar epistémico a partir del cual las nuevas humanidades proyectarían la condición ya no del profesor como el profesional titulado, sino como el que profesa, profetisa, declara y testimonia.

d. Las humanidades y la performatividad: finalmente, las humanidades vistas como el acto profesoral donde se entrega un testimonio, son en principio un que hacer responsable sobre un modo particular de entregar un saber en el hablar. Entendiendo con ello que la enseñanza de las humanidades depende 
en gran medida del acto de fe, tácitamente juramentado que depositó el oyente que escucha la lección de quien da testimonio o profesa (habla), sobre algo que posee un cierto valor sagrado, indeterminado. Este acto de fe que se entrega al oyente, mediante la palabra o testimonio que imparte el maestro, y que este a su vez ha depositado hacia una forma aproximada de verdad no empírica ni demostrable, mantiene una tensión performativa que se aproximaría al lenguaje de la fábula y la ficción. Profesar sobre algo es de facto una práctica discursiva del tipo performativo. La performatividad que caracteriza al discurso de las humanidades se entiende entonces como un pacto moral, donde se pone en juego la responsabilidad y el compromiso del testimonio.

\section{Las gramáticas del futuro: la redención de la humanidad o la venida del homo religiusus}

En la actualidad la literatura que ha versado sobre la antropología educativa es extensa. Los enfoques culturalistas, conductistas, psicologistas, estructuralistas, etc., están a la orden del día para dar cuenta de las diversas maneras que desde la antropología se han delineado marcos de referencia tanto teóricos como metodológicos sobre el modelo de ser humano que se pretende educar. Todas, con sus matices ideológicos y de tendencias metodológicas distintas, presuponen que el papel formativo de la educación gira en torno a una proyección de hombre que se pretende promocionar en la sociedad.

La posible justificación del hecho de que un antropólogo se dirija a pedagogos es que la antropología -o tal vez mejor las antropologíassiempre, de una manera u otra, ha sido -y es- una praxis pedagógica; directa $u$ oblicuamente, las pedagogías y las antropologías se han constituido a partir de la respuesta explícita o implícita del pedagogo o del antropólogo al interrogante pedagógico y antropológico por excelencia: ¿qué es el ser humano? (Duch, 2004: 159).

Antropólogos y pedagogos se encuentran en el límite de la pregunta que indaga acerca de la esencia del hombre. Más allá de las contingencias que rodean la institucionalización pedagógica, administrativa e investigativa de la educación, el ideal sobre el cual se orientará la acción didáctica como la finalidad educativa, lleva por delante una relativa concepción de ser humano que se pretende formar:

Pero lo más relevante para toda pedagogía es que ésta debe preguntarse necesariamente por el hombre. Su concepción marcará las formas de "hacer pedagogía», de concebir al otro y sus posibilidades de subjetivarse, más allá de las tecnologías, las programaciones, las clases, los objetivos, las competencias, las evaluaciones, los pasillos y los patios, los profesores y los alumnos, etc. (Planella, 2007:10). 
Ahora bien, el reconocimiento de que la antropología y la pedagogía retomarían la pregunta universal de ¿Qué es el hombre?, está confrontada con las sucesivas crisis axiológicas y económicas experimentadas en una sociedad actual, cuya sintomatología se caracteriza por la pauperización de la vida, la anomalía de las estructuras sociales (escuela, familia, Estado), junto a las patologías que atacan a los individuos en los órdenes emocional, físicos y psicológicas. En el escenario actual el cuadro de las enfermedades sociales va en aumento. La paulatina desvalorización de los ideales morales, en otrora considerados como absolutos e innegociables, son ahora monedas de papel; las desigualdades sociales y el desempleo creciente, crean un ambiente desesperanzado y derrotista que siembra el escepticismo sobre las posibilidades de una «vida buena» en la sociedad actual, donde se globalizan las miserias y se exportan las crisis económicas; la ausencia de los metarelatos que prescriban y describan la regularidad de un modus vivendi ideal, en el que tienen lugar la armonización con el otro (prójimo), el mundo (medio ambiente) y Dios, es sustituido por la desconfianza y la insolidaridad, la contaminación y en síntesis el ateísmo, actitud negadora de la creencia en la existencia de una fuerza unificadora superior.

Lluís Duch plantea que tanto antropólogos como pedagogos están llamados a ser los nuevos «[...] terapeutas del tiempo y el espacio humanos» (Duch, 2004:160). La cura o el paliativo para disminuir el efecto destructor de los nuevos males de Occidente está en manos de una práctica educativa que trasmita «[...] resistencias de lo humano frente al caos» (Duch, 2004: 160).

La transmisión de saberes se presenta en la práctica como el conjunto de acciones pedagógicas de resistencia, encaminadas a la no desaparición de la educación con vocación humanista. Para que las humanidades sean asumidas como prácticas pedagógicas de resistencia, es necesario recurrir al lenguaje expresivo de la ética y la estética. Así como en el mundo griego, azteca o inca, tuvo un valor decisivo la plasticidad del espíritu, esto es, la materialización de una inteligencia simbólica orientada a la invención de diversos estilos de vida (el del chaman, el filósofo, el gobernante, el ciudadano, el campesino, etc.), en la actualidad, resulta necesario retomar al concepto de «cultura ejemplar», para cualificar la vida, hoy día expuesta al caos de la información y a la masificación de la capacitación en el conocimiento de habilidades técnicas . La educación pensada antropológicamente deviene -según el mismo autor- en una «praxis de la dominación de la contingencia» (Duch, 2004: 161).

El proceso civilizatorio en Occidente no ha dejado más que ruinas y atraso para las regiones que han decidido participar de la globalización. Partiendo de las prácticas coloniales en América en el siglo XV, pasando por las del siglo XIX que llevaron a cabo Europa y Norteamérica en África y Asia, con las dos primeras guerras mundiales y el holocausto nazi, hasta la polarización ideológica a mediados del siglo XX, y la confrontación entre política y religión que se produce en el siglo XXI, la invención de lo humano ha experimentado 
históricamente una negación sistemática, que ha venido a confirmar su situación de inercia y de nihilismo total.

De la mano de Eliade y Berger, Duch sostiene que la consolidación de una práctica educativa que retenga lo humano, necesitará ya no de un proceso de civilización sino de «cosmización» de las culturas que, contrarreste la «caotización» que se vive en el mundo actual, en el que predomina la saturación de la información, la banalización del bien absoluto por todas las formas de hacer el mal, la liquidez de las relaciones afectivas y en consecuencia la paulatina destrucción de los centros nucleares de la sociedad (la familia, la religión y el Estado).

La transmisión del cosmos que retiene lo humano, es al mismo tiempo una introducción a las gramáticas del futuro. Es a partir de un lenguaje religioso plagado de imágenes bellas y de actos ejemplares, como se va construyendo la redención de la humanidad, que le apuesta ya no a la venida del homo sapiens, modelo antropológico de las teorías sociales progresistas que se desarrollaron en la ilustración europea del siglo XVIII, y en las que se sobrevaloraba el poder de la ciencia y la técnica en la solución de todos los problemas que aquejan a la humanidad, o del homo faber, otro paradigma que ha dominado desde el siglo XIX, época marcada por el desarrollo fabril desatada por la revolución industrial, y que ha promovido los valores económicos del capital, el trabajo, el consumo, la compra y la venta, etc. Tanto en la teoría del homo sapiens como en la del homo faber se niegan sistemáticamente las posibilidades de una redención de la humanidad. Son modelos antropológicos donde la esperanza, la espiritualidad y la salud permanecen en el silencio.

Para Duch es en la vigencia de la preocupación metafísica donde se podrá retener el valor absoluto de lo humano, en contravía a la esclavización de los intereses materiales, el afán de consumo, la seducción del mercado, el exitismo, fenómenos dominados por las gramáticas del nihilismo. Se trata en el fondo de retener en las transmisiones formativas que se producen en el mundo de la virtualidad, las expresiones éticas y estéticas que se desprenden del homo symbolicus que planteaba el neokantiano Ernst Cassirer y que Duch pone a dialogar de manera sugerente con el homo religiusus de la teología cristiana.

La etimología latina de la palabra religión hace referencia a la religación del hombre con Dios. Duch propone ampliar las religaciones con el espacio y el tiempo que habita el otro. Para el teólogo español, el humanismo ya no puede ser pensado como un principio de universalidad donde se privilegian la razón, la ciencia, las lenguas antiguas, una idea de felicidad, etc. Como lo plantea Unamuno en El sentimiento trágico de la vida, la filosofía no habla del ser humano abstracto y general, del cual parte el ideal formativo de las humanidades clásicas, sino del singular concreto que además de ser una entidad compuesta de carne y hueso, es un prisionero de la historia o la encarnación viva de una geografía, valores y tradiciones específicos; se trata, pues, de habilitar 
las humanidades en la subjetividad que padece el mundo desde una situación particular y la cual está volcada a establecer relaciones con otra subjetividad, dentro de una estructura espacio temporal compartida, y que hoy día prescinde de los espacios presenciales, de la escritura a mano alzada, de la conversación real, etc.

En otras palabras, las religaciones con el otro no se dan en el plano de la conciencia sino de la contingencia. Por lo tanto, los nuevos procesos de transmisión de conocimiento tendrán que vérselas con las gramáticas del futuro o los lenguajes que se han construido a partir de los dispositivos tecnológicos de la comunicación (TIC). Si bien no resulta fructífero regresar a una fundamentación general de la idea de humanidad, es pertinente rastrear en la contingencia la «esperanza cósmica» de redimir la religación del hombre con la humanidad en medio de un mundo «caóticamente escéptico»:

La finalidad última de la praxis antropológica y pedagógica [...] consiste en una configuración saludable y gozosa de la relacionalidad humana. [...]. Ahora bien, referirse a la relacionalidad humana como plasmación histórica de su espacio-temporalidad implica no referirse a la Historia, sino a la multiplicidad de historias y peripecias biográficas que configuran - a menudo desfiguran- el trayecto existencial desde el nacimiento hasta la muerte de cada uno de nosotros. En realidad, nuestras historias constituyen el resumen o el precipitado vital y narrativo de las sucesivas asociaciones del espacio y del tiempo que hilvanan el tejido de toda nuestra existencia humana (Duch, 2004: 165).

Relacionalidad que se ha complejizado al reconocer que la inteligencia simbólica se despliega activamente en las múltiples narraciones que configuran la relación del yo con el espacio tiempo. Antropología y pedagogía actuarían como ámbitos disciplinares que conjuntamente pensarían modelos de aprendizaje donde la formación de lo humano privilegiaría el reconocimiento de la diversidad de los lenguajes de cara a las formaciones discursivas habituales y monótonas.

Como lo sostiene Cassirer, los espacios físicos comienzan a ceder ante el universo de los nuevos espacios artificiales, donde las definiciones de lo humano ya no permanecen ancladas a la ontología de la sustancialidad, la presencialidad y la pasividad. El lenguaje de los símbolos es funcional porque es un «sistema de relaciones» o «urdimbres de sentido», que logran capturar la complejidad, la dinámica y la creatividad que caracteriza al lenguaje artificial:

El lenguaje, el mito, el arte y la religión constituyen partes de este universo, forman los diversos hilos que tejen la red simbólica, la urdimbre complicada de la experiencia humana. Todo progreso en pensamiento y experiencia afina y refuerza esta red. El hombre no puede enfrentarse ya con la realidad de un modo inmediato; no puede verla, como si dijéramos, 
cara a cara. La realidad física parece retroceder en la misma proporción que avanza la actividad simbólica. En lugar de tratar con las cosas mismas, en cierto sentido, conversa constantemente consigo mismo. Se ha envuelto en formas lingüisticas, en imágenes artísticas, en símbolos míticos o en ritos religiosos, en tal forma que no puede ver o conocer nada sino a través de la interposición de este medio artificial (Cassirer, 1996: 48).

\section{Conclusión}

Establecer un denominador común que resuma cada uno de los aportes expuestos es una tarea difícil. Pero lo cierto es que las humanidades, en diferentes lugares del mundo, y en las múltiples perspectivas representadas por una élite cultivada alrededor de unas tradiciones filosóficas particulares, destacadas en el trascurso de una centuria, que va de finales del siglo XIX hasta las postrimerías del siglo XXI, son consideradas como un conjunto de discursos que postulan unos modelos de humanización a contraluz de las dinámicas sociales que han trastocado el concepto mismo de humanidad, particularmente a partir del desarrollo industrial del capitalismo del siglo XIX, hasta incursionar en el modelo de la democracia dentro de las dinámicas de la interculturalidad ínsitas en el capitalismo global del siglo XX y que se han plegado en el fenómeno histórico de la mundialización, a través de la virtualidad y la deslocalización de los discursos, un lenguaje característico de la tercera revolución tecnológica del capitalismo en el siglo XXI, y en el que las concepciones tradicionales del trabajo y de la profesión, han girado radicalmente en dirección al teletrabajo y a la virtualización de los procesos de producción de conocimiento técnico-científico ${ }^{7}$.

En otras palabras, las humanidades a partir del siglo XIX han sido una serie de discursos que han leído el proceso histórico del capitalismo, en sus diferentes mutaciones locales y globales, de tal suerte que la relación entre humanismo, universidad y educación se problematiza y tensiona. El reducto de humanidad por el cual se plantea una reconstrucción de la idea de hombre viaja a través del lenguaje de los símbolos, las metáforas y el arte. Una hipótesis rastreada desde los relatos novelados por las élites letradas colonizadoras (en clave de Said), que han construido una imagen borrosa y sesgada del otro, acomodada a los intereses expansionistas de las potencias de turno, hasta considerar a las humanidades como una serie de testimonios profesados bien sea desde una conciencia ética (performatividad formulada por Derrida) o religiosa (en la perspectiva teológica de Duch). En estas dos propuestas las humanidades caminan en dirección a la virtualidad, un nuevo espacio colonizado por el mercado, en el marco histórico de la tercera revolución industrial. 
Bien sea desde la versión expansionista e intervencionista de la nordomanía definida por José Enrique Rodo, quien a finales del siglo XIX en Latinoamérica, cuestionaba cómo el espíritu utilitarista y de producción material representado en la figura literaria de Calibán, campeaba entre los programas políticos y educativos de los países latinoamericanos, o en la mirada de la democracia liberal, característica del capitalismo del siglo XX, y que de una u otra forma es interpretada por Martha Nussbaum, al considerar las humanidades como un conocimiento necesario para la consolidación de los valores democráticos, en aras a equilibrar la tendencia creciente hacia la formación técnico instrumental. Para la filósofa, las universidades están llamadas a consolidar el proceso de la democratización de los conocimientos humanísticos, mientras que el sistema capitalista se enriquece y prospera con una nueva generación de profesionales capacitados en el reconocimiento de las herencias culturales y las contradicciones sociales desatadas en las sociedades que participan del gran concierto global del intercambio económico.

Otra perspectiva histórica de la relación humanismo y capitalismo es la del filósofo palestino Edward Said, quien desde los estudios culturales, plantea una crítica al colonialismo de finales del siglo XIX, donde las naciones imperiales (Inglaterra, Francia, Alemania, Italia, Portugal y España), impulsaron la formación de una élite intelectual en las universidades que a lo largo del siglo XX dirigió su mirada al pasado exótico de las culturas de la antigua babilonia, haciendo una cartografía e inventario de las riquezas del imperio en las colonias, desconociendo al mismo tiempo las gramáticas culturales de una periferia cuya humanidad ha permanecido oculta y silenciada. Para Said el peligro de unas humanidades entendidas como el conjunto de conocimientos históricos que definen el haber cultural de un pueblo (que encaja en la visión eurocéntrica del helenismo jaegeriano), consiste en su ceguera para comprender que la relación entre el imperio y la cultura, no solamente implica la memoria sobre el legado de unas tradiciones letradas heredadas, sino también las historias y los relatos de las periferias desplazadas, explotadas y desaparecidas, que en lugar de hacer la historia de los vencedores, relata los dramas y las angustias de los vencidos.

Para Jacques Derrida el talante de universalidad que caracteriza al lenguaje de las humanidades, es una herencia del proceso de mundialización que atravesó Europa en el siglo XVIII con la declaración de los derechos del hombre y el ciudadano. Este proceso ha hecho que las humanidades sean herederas de una performatividad donde praxis y discurso se encuentran en un compromiso declarativo, profesado e inserto -paradójicamente- en las dinámicas del mercado laboral, donde la virtualidad y el teletrabajo, cambian sustancialmente los conceptos de producción y tiempo del conocimiento. Estos fenómenos obedecen a la tercera revolución tecnológica del capitalismo, acontecimiento histórico que determinará la enseñanza del humanismo en la universidad del futuro. 
Tal vez, como lo plantea Duch, las gramáticas del futuro serán los nuevos escenarios donde tendrá lugar la enseñanza de las humanidades en la universidad. Su misión será la de devenir en un discurso que profesará una nueva evangelización (la de la sacralización de la virtualidad), que batallará contra las gramáticas del nihilismo, hasta predicar el valor absoluto de la vida, la esperanza, y los deseos de una bienaventuranza que humanice el uso de las nuevas tecnologías de la comunicación. En la propuesta de Duch resuenan las ideas derrideanas acerca de las humanidades y su relación con la práctica confesional y testimonial, que profesa una palabra y al mismo tiempo una creencia, en fin, con la performatividad que caracteriza a un uso del lenguaje, que no solamente dice sino que también hace con relación a un sistema axiológico donde el otro hace parte de la construcción de un sí mismo moral, etc.

Empero, esta especie de sacralización del lenguaje de las humanidades le resta potencia crítica y de deconstrucción, además de poner en riesgo el valor testimonial de la palabra al devenir rápido y eficaz de los lenguajes virtuales, donde los sistemas de vigilancia y control (p.ej. para acceder a una cuenta de correo electrónico se necesita de una clave), logran desvincular la relación entre el habla y la acción, para convertir las humanidades en un conjunto de «saberes vitrina», que se encuentran a la mano para consultar la palabra desconocida en un buscador de información o en su defecto en una biblioteca virtual.

\section{Referencias bibliográficas}

Ainsa, F. 2002. El centenario de Ariel: una lectura para el 2000. En: L. Zea y H. Toboada (compiladores). Latinoamérica en la globalización y el tercer milenio. Arielismo y globalización. Vol. 2. México: F.C.E

Cassirer, E. 1996. Antropología filosófica. Bogotá: F. C. E.

Castro, S. 2010. La hybris del punto cero. Ciencia, raza e ilustración en la Nueva Granada (1750-1816). Bogotá: Editorial Pontificia Universidad Javeriana.

Duch, L. 2004. Estaciones del laberinto. Ensayos de antropología. Barcelona: Herder.

De León, E. 2002. Ariel cien años después: modernización suave y subjetividad. En: L. Zea y H. Toboada (compiladores). Latinoamérica en la globalización y el tercer milenio. Arielismo y globalización. Pp. 13-31. Vol. 2. México: F.C.E.

Derrida, J. 2002. La universidad sin condición. Madrid: Ed. Trotta.

Gastelumendi, A.2002. La razón rodoniana. En: L. Zea y H. Toboada (compiladores). Latinoamérica en la globalización y el tercer milenio. Arielismo y globalización. Pp. 5159. Vol. 2. México: F.C.E. 
Gigon, O. 1965. Werner Jaeger y su obra. Revista ECO. Revista de la cultura de occidente. Octubre, Tomo XI/ 6: 631-646.

Gutiérrez, R. 1986. Universidad y sociedad. Revista Argumentos. Universidad y Sociedad. 14/15, 16/17: 63-79.

Jaeger. W. 1997. Paideia. Los ideales de la cultura griega. México: F.C.E.

Nussbaum, M. 2010. Sin ánimo de lucro. Por qué la democracia necesita de las humanidades. Buenos Aires: Katz.

Planella, J. 2007. Los entresijos de la antropología de la educación. En: Poéticas de la humanización: miradas de la antropología pedagógica. Pp. 13-24. Barcelona: Editorial UOC.

Rifkin, J. 1997. El fin del trabajo. Nuevas tecnologías contra puestos de trabajo: el nacimiento de una nueva era. Barcelona: Paidós.

Said, E. 2006. Cultura e imperialismo. Barcelona: Anagrama.

Said, E. 2009. Orientalismo. México: Random House Mondadori.

Souriau, E. 2010. Diccionario de estética. Madrid: Akal.

Walzer, H. y Seel, M. 2007. Las paradojas de la utilidad: un debate sobre las humanidades. Revista de Occidente. Junio. $\mathrm{N}^{\circ}$ 313: 5-16.

Zea, L. y Toboada, H. (compiladores). 2002. Latinoamérica en la globalización y el tercer milenio. Arielismo y globalización. Vol. 2. México: F.C.E. 